\title{
Autosomal Recessive Polycystic Kidney Disease and Epidemiologic
}

\section{Factors}

\author{
Parsa Yousefichaijan, ${ }^{1}$ Fereshte Maghsudlu, ${ }^{2,}{ }^{*}$ and Mohammad Rafiei ${ }^{3}$ \\ ${ }^{1}$ Amirkabir Hospital, Department of Pediatric Nephrology, School of Medicine, Arak University of Medical Sciences, Arak, Iran \\ ${ }^{2}$ Students Research Committee, School of Medicine, Arak University of Medical Sciences, Arak, Iran \\ ${ }^{3}$ Department of Biostatistics, School of Medicine, Arak University of Medical Sciences, Arak, Iran \\ "Corresponding author: Fereshte Maghsudlu, Students Research Committee, Arak University of Medical Sciences, Arak, Iran. Tel: +98-9112737631, Fax: +98-8633133858, E-mail: \\ fereshte.maghsoudlou@yahoo.com; fmaghsudlu@arakmu.ac.ir
}

Received 2016 August 01; Revised 2016 December 22; Accepted 2017 January 13.

\begin{abstract}
Background: Autosomal recessive polycystic kidney disease (ARPKD) is a heterogeneous inherited disorder most commonly seen in childhood. The presentation is usually a palpable large mass in the flank or abdomen appearing at infancy or birth, leading to electrolyte abnormalities, pulmonary hypoplasia, oligohydramnious and the Potter's syndrome. The survival rate of this disease is 70\%. Multiple mutations of the polycystic kidney and hepatic disease 1(PKHD1) are known that can cause ARPKD. On the other hand, mutations in PKHD1 have also been identified in about 30\% of children with congenital hepatic fibrosis (the Caroli's syndrome) without any evidence of kidney involvement. Based on this evidence, not everyone with PKHD1 mutations will present with ARPKD. Recent studies have shown that nongenetic factors, including environmental exposures had a significant effect on manifestations of ARPKD. The present study aimed at investigating the possible link between ARPKD and its epidemiologic factors, hypothesizing that these epidemiologic conditions would influence the incidence of ARPKD.

Objectives: The present study aimed at evaluating a possible link between the ARPKD and its epidemiologic factors.

Methods: In this case-control study, children with ARPKD referred to Amirkabir hospital in Arak city, Iran, were compared with noninfected children. Examinations, interviews, and questionnaires were performed to collect data and the disease was diagnosed by a physician.

Results: The results of this study showed no significant relationship between epidemiological factors such as age, place of residence for families, sex, family education/occupation/ income, body mass index, stunted growth, slow growth, good growth, milk intake, water intake, failure to thrive and ARPKD.
\end{abstract}

Conclusions: Based on our findings, epidemiological factors did not have a significant effect on the occurrence of ARPKD.

Keywords: ARPKD, Renal Cyst, Epidemiologic Factors, Children

\section{Background}

The cystic renal disorders are a heterogeneous and hereditary disease described by cystic changes in the kidneys. The two major inherited types are the autosomal recessive polycystic kidney disease (ARPKD) and autosomal dominant polycystic kidney disease $(1,2)$. The autosomal recessive polycystic kidney disease is a comparatively usual form of the childhood polycystic kidney disease and the frequency of it is 1: 20000 in neonates (3). Different degrees of hepatic anomalies are connected with renal changes in ARPKD, biliary dysgenesis and hepatic fibrosis are included (4). The kidneys are enlarged, with small cysts, $<5 \mathrm{~mm}$, limited to the collecting tubules (5). The autosomal recessive polycystic kidney disease is most often diagnosed by third trimester antenatal ultrasounds that may demonstrate oligohydramnios, flank masses, or absence of fetal vesicle filling. If it remains antenatally undiagnosed, delivery of neonates may be difficult due to large masses in flank (4). Palpable masses in flank and a large liver are the most usual primary presentations of ARPKD leading to respiratory insufficiency, hypertension and urinary tract infections (3). The autosomal recessive polycystic kidney disease may followed by electrolyte abnormalities, pulmonary hypoplasia, oligohydramnious and the Potter's syndrome (6). Thirty percent of patients who present with large kidneys die in the infancy due to respiratory inadequacy and presumably many of these cases have undiagnosed ARPKD (4). Different mutations of PKHD1 are known that can cause ARPKD and their average detection rate is almost $85 \%$ (7). On the other hand, mutations in PKHD1 have also been identified in about $30 \%$ of children with congenital hepatic fibrosis (the Caroli's syndrome) without evident kidney involvement (5). In recent years, molecular analysis of patients and comprehensive studies of sibling have shown the effect of the factors described in a variety of monogenic diseases. Exploration of the genetic cause of the polycystic kidney disease (PKD) in humans re- 
vealed that genotype-phenotype correlations are now possible in these disorders. It is certainly estimated that nongenetic factors, including environmental exposures, significantly influence the severity of renal disease and other extrarenal manifestations in PKD (8).

\section{Objectives}

The present study aimed at investigating the possible link between ARPKD and its epidemiologic factors, hypothesizing that these epidemiologic conditions would increase the risk of ARPKD.

\section{Methods}

In this case-control study, 60 children with ARPKD and 60 noninfected children were studied during 1 year. The study size was determined by our statistics consultant and samples were randomly selected. Our inclusion criterion was ARPKD based on the physician's diagnosis. The exclusion criterion was parents' disagreement regarding their children's participation in our study. Patients were diagnosed based on Specific diagnostic criteria of ARPKD:

- Typical findings on renal imaging and,

- One or more of the following:

- Imaging findings consistent with biliary ductal ectasia.

- Clinical/laboratory signs of congenital hepatic fibrosis (CHF) that leads to portal hypertension and may be indicated by hepatosplenomegaly and/or esophageal varices.

- Hepatobiliary pathology demonstrating a characteristic developmental biliary ductal plate abnormality and resultant $\mathrm{CHF}$.

- Absence of renal enlargement and/or characteristic imaging findings in both parents, as demonstrated by high-resolution ultrasonography (HRUS) examination.

- Pathologic (biopsy or autopsy) or genetic diagnosis of ARPKD in an affected sib (9).

We evaluated epidemiologic characteristics of the patients and used logistic regression analysis to measure the possible link between ARPKD and its epidemiologic factors. Epidemiologic characteristics were 1) age at diagnosis of $\operatorname{ARPKD}(<2,3-6,7-12$ and $12<$ months), 2) sex (male and female), 3 ) family education (below high school, high school diploma, Bachelor's degree and master's degree), 4) family occupation: (employee, worker, self-employment and housewife for mothers), 5) the average monthly salary of family $(<300,300-600$ and $600<\$)$, 6) drinking water (tap water or purified water with household devices), 7) failure to thrive (FTT), 8) stunted growth, 9) slow growth, 10) good growth, 11) milk intake (maternal milk or powdered milk), 12) infant body mass index (BMI, $\mathrm{kg} / \mathrm{m}^{2}$ ), 13) place of residence in urban or rural areas, and 14) gestational week (preterm < 37, term 37-42, and postterm $>42$ ). Data were analyzed using the SPSS software version 18.

\section{Results}

The mean age of the studied infants was 11 months at the time of ARPKD diagnosis. The mean age of the control group was 20 months (Table 1). A domination of one gender among the case or control group was not observed (58.3\% of the cases and $63.3 \%$ of the controls were females). The distribution of all studied epidemiologic factors was similar in the two groups (Table 2). Regarding the growth status, FTT was not observed in the cases or controls. Stunted growth was found in $16.6 \%$ of the cases and controls $(P=1)$. Also, $28.3 \%$ of the cases and $25 \%$ of the controls had slow growth $(\mathrm{P}=0.978) ; 55 \%$ of the cases and $58.3 \%$ of the controls had good growth $(\mathrm{P}=0.978)$. Eighty-five percent of the cases and controls were fed with maternal milk $(\mathrm{P}=1)$. Moreover, $88.3 \%$ of the cases and controls lived in urban areas $(\mathrm{P}=1)$.

\section{Discussion}

We conducted this study to evaluate a possible link between ARPKD and its epidemiologic factors, to distinguish predictors that may influence the penetration of PKHD1.According to the results of the present study; there was no significant correlation between the studied factors and frequency of ARPKD. Early death in infancy, endstage renal disease (ESRD) in survivals and symptom-free patients until old age are the variable phenotypes of PKD (10-13), which indicate that genetic is not the only effective factor in this disease (8). Recent studies have shown that environmental factors are one of the causes of phenotypic variability in PKD (8). Male hormonal factors, caffeine exposure and smoking have been shown to be as predisposing factors for rapid growth of the renal cyst, increasing the risk of CKD and ESRD in patients with the renal disease including the ADPKD (14-17). Among men, early onset of hypertension, and early and frequent gross hematuria, and among women, three or more pregnancies are also known as predictors associated with ADPKD (18).

\subsection{Conclusion}

We hope that our findings will provide the impetus for more comprehensives studies in future to determine the predisposing conditions and clinical consequences of children with ARPKD with the aim of studying the pathophysiology due to better management of ARPKD and to evaluate even if adjustment of these conditions can influence 
Table 1. Distribution of Age in the Study Group ${ }^{\mathrm{a}}$

\begin{tabular}{lccccc}
\hline Age, Month & $<\mathbf{2}$ & $\mathbf{3 - 7}$ & $\mathbf{7 - 1 2}$ & \multicolumn{1}{c}{ Mean } \\
\hline Case & $9(15)$ & $22(36.6)$ & $14(23.3)$ & $15(25)$ & 11.01 \\
Control & 0 & 0 & $14(23.3)$ & 20.5 & $46(76.6)$ \\
\hline
\end{tabular}

${ }^{\mathrm{a}}$ Values are expressed as No. (\%).

Table 2. Epidemiologic Characteristics of the Study Group ${ }^{\mathrm{a}}$

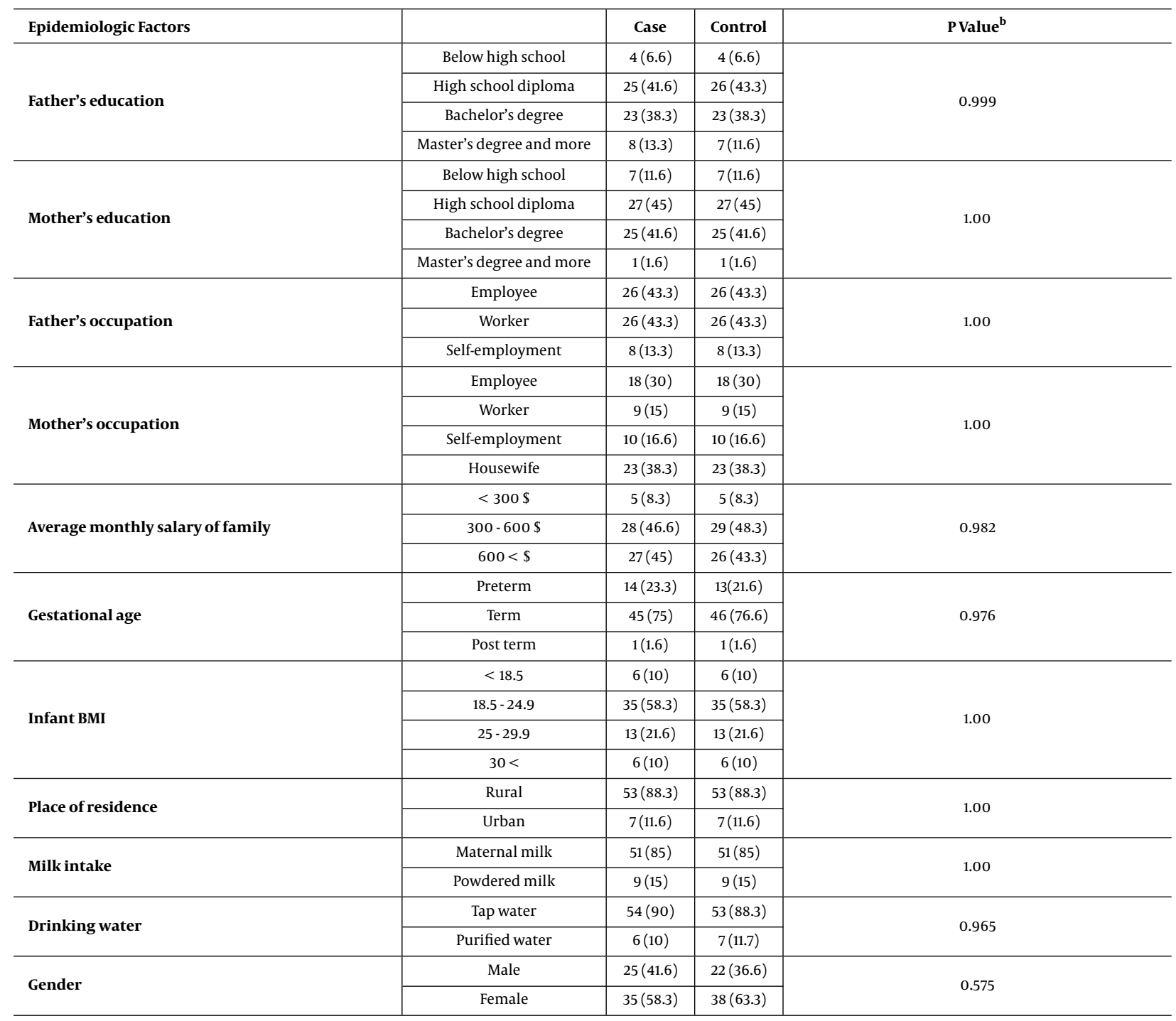

Abbreviation: BMI, body mass index.

${ }^{\mathrm{a}}$ Values are expressed as No. (\%).

${ }^{\mathrm{b}} \mathrm{P}$ values less than 0.05 were considered significant.

the frequency of ARPKD. As mentioned before, some recent studies have shown that there are some nongenetic conditions that influence the PKD. Probably the reason of finding no correlation between environmental factors and the frequency of ARPKD is due to the strong effect of genetic factors. Another reason may be the small population of our 
study and limited factors, which had been evaluated.

\subsection{Limitations of the Study}

A limitation of our study was a small proportion of patients. We suggest multicentric studies on this aspect of kidney diseases.

\section{Acknowledgments}

The authors gratefully acknowledge the research council of Arak University of Medical Sciences (grant number: 2387) for the financial support.

\section{Footnotes}

Authors' Contribution: Parsa Yousefichaijan: manuscript preparation, and data collection; Mohammad Rafeie: drafting of the manuscript; and Fereshte Maghsudlu: manuscript preparation, data analysis, and manuscript revision; all authors read and approved the final manuscript.

Financial Disclosure: This study was financially supported by the Arak University of Medical Sciences, Arak, Iran.

Funding/Support: This study was supported in part by the Arak University of Medical Sciences (grant 2387).

\section{References}

1. Kaplan BS, Meyers K. Developmental abnormalities of the kidneys. 1 ed. Philadelphia: Elsevier Mosby; 2004. pp. 223-30.

2. Sweeney WE, Avner ED. Diagnosis and management of childhood polycystic kidney disease. Pediatr Nephrol. 2011;26(5):675-92. doi: 10.1007/s00467-010-1656-1. [PubMed: 21046169].

3. Capisonda R, Phan V, Traubuci J, Daneman A, Balfe JW, Guay-Woodford LM. Autosomal recessive polycystic kidney disease: outcomes from a single-center experience. Pediatr Nephrol. 2003;18(2):119-26. doi: 10.1007/s00467-002-1021-0. [PubMed: 12579400].

4. Verghese P, Miyashita Y. Neonatal polycystic kidney disease. Clin Perinatol. 2014;41(3):543-60. doi: 10.1016/j.clp.2014.05.005. [PubMed: 25155726].

5. Longo D, Fauci A, Kasper D, Hauser S, Jameson J, Loscalzo J. Polycystic Kidney Disease and Other Inherited Tubular Disorders. 18 ed. USA: McGraw-Hill Companies Inc; 2012.
6. Al Salmi I, Hoy WE, Kondalsamy-Chennakes S, Wang Z, Healy H, Shaw JE. Birth weight and stages of CKD: a case-control study in an Australian population. Am J Kidney Dis. 2008;52(6):1070-8. doi: 10.1053/j.ajkd.2008.04.028. [PubMed:18640755].

7. Kliegman RM, Behrman RE, Jenson HB, Stanton BM. Nelson textbook of pediatrics. Elsevier Health Sciences; 2007

8. Rossetti S, Harris PC. Genotype-phenotype correlations in autosomal dominant and autosomal recessive polycystic kidney disease. JAm Soc Nephrol. 2007;18(5):1374-80. doi: 10.1681/ASN.2007010125. [PubMed: 17429049].

9. Sweeney WE, Avner ED. Pathophysiology of childhood polycystic kidney diseases: new insights into disease-specific therapy. Pediatr Res. 2014;75(1-2):148-57. doi: 10.1038/pr.2013.191. [PubMed: 24336431].

10. Bergmann C, Senderek J, Windelen E, Kupper F, Middeldorf I, Schneider F, et al. Clinical consequences of PKHD1 mutations in 164 patients with autosomal-recessive polycystic kidney disease (ARPKD). Kidney Int. 2005;67(3):829-48. doi: 10.1111/j.1523-1755.2005.00148.x. [PubMed: 15698423].

11. Fick GM, Johnson AM, Strain JD, Kimberling WJ, Kumar S, MancoJohnson ML, et al. Characteristics of very early onset autosomal dominant polycystic kidney disease. J Am Soc Nephrol. 1993;3(12):1863-70. doi: 10.1007/bf01213346. [PubMed: 8338917].

12. Guay-Woodford LM, Desmond RA. Autosomal recessive polycystic kidney disease: the clinical experience in North America. Pediatrics. 2003;111(5 Pt 1):1072-80. doi: 10.1542/peds.111.5.1072. [PubMed: 12728091].

13. Zerres K, Rudnik-Schoneborn S, Deget F. Childhood onset autosomal dominant polycystic kidney disease in sibs: clinical picture and recurrence risk. German Working Group on Paediatric Nephrology (Arbeitsgemeinschaft fur Padiatrische Nephrologie. J Med Genet 1993;30(7):583-8. doi: 10.1136/jmg.30.7.583. [PubMed: 8411032].

14. Belibi FA, Wallace DP, Yamaguchi T, Christensen M, Reif G, Grantham JJ. The effect of caffeine on renal epithelial cells from patients with autosomal dominant polycystic kidney disease. J Am Soc Nephrol. 2002;13(11):2723-9. doi: 10.1097/01.ASN.0000025282.48298.7B. [PubMed: 12397042].

15. Harris PC, Bae KT, Rossetti S, Torres VE, Grantham JJ, Chapman AB, et al. Cyst number but not the rate of cystic growth is associated with the mutated gene in autosomal dominant polycystic kidney disease. J Am Soc Nephrol. 2006;17(11):3013-9. doi: 10.1681/ASN.2006080835. [PubMed: 17035604].

16. Klahr S, Breyer JA, Beck GJ, Dennis VW, Hartman JA, Roth D, et al. Dietary protein restriction, blood pressure control, and the progression of polycystic kidney disease. Modification of Diet in Renal Disease Study Group. J Am Soc Nephrol. 1995;5(12):2037-47. [PubMed: 7579052].

17. Orth SR, Stockmann A, Conradt C, Ritz E, Ferro M, Kreusser W, et al. Smoking as a risk factor for end-stage renal failure in men with primary renal disease. Kidney Int. 1998;54(3):926-31. doi: 10.1046/j.1523 1755.1998.00067.x. [PubMed: 9734618].

18. Schrier RW, Brosnahan G, Cadnapaphornchai MA, Chonchol M, Friend K, Gitomer B. Predictors of autosomal dominant polycystic kidney disease progression. J Am Society Nephrol. 2014. 